\title{
Wind Effects on Apple in the Eastern United States
}

\author{
Richard P. Marini ${ }^{1}$ and John A. Barden \\ Department of Horticulture, Virginia Polytechnic Institute and State University, Blacksburg, VA 24061-0327 \\ James R. Schupp \\ Department of Horticultural Sciences, Cornell University, The Hudson Valley Laboratory, Box 727, Highland, \\ NY 12528
}

Most apple (Malus $\times$ domestica Borkh.) producing regions of the United States are located far enough inland so that hurricane damage is rare. However, occasionally the mid-Atlantic region and New England suffer damage from hurricanes that have deteriorated to tropical storms, and the orchards in the Great Lakes region may experience damage from severe windstorms. Damage associated with severe wind events has not been frequent enough to stimulate research on how to treat injured trees after a storm. Additionally, there are no quantitative data in the literature from replicated experiments where trees were treated differently following a storm. Therefore, all of the information available concerning the susceptibility of apple trees to wind events and how injured trees should be treated following a storm is based on orchard observations rather than replicated experiments yielding data that could be analyzed statistically.

Many apple trees planted in the past decade are on dwarfing rootstocks, and are prone to leaning because the roots are brittle. To prevent leaning and limb breakage (Elfving and McKibbon, 1992) and to obtain maximum yields (Barden and Marini, 1998) most trees on such rootstocks are supported by posts or a trellis, but high winds can still cause tree damage if support systems are not constructed properly. Poorly constructed support systems usually involve posts that are weak, end posts not driven deep enough, and individual tree posts that are not securely fastened to an overhead wire. Observations indicate that factors contributing to susceptibility of trees to wind damage include soil type, age of trees, exposure to wind, crop load, rootstock/ scion combination, quality of the support system, and the width of the herbicide strip. Tree uprooting tends to be most severe on light or shallow soils, when trees carry a heavy crop, or are supported inadequately, and when vegetation is not allowed to grow under the trees. Because experimental data are totally lacking for most of these factors,

Received for publication 26 May 2000. Accepted for publication 13 June 2000. The cost of publishing this paper was defrayed in part by the payment of page charges. Under postal regulations, this paper therefore must be hereby marked advertisement solely to indicate this fact.

${ }^{1}$ Corresponding author. E-mail address: marinir@ vt.edu this discussion will concentrate on the effect of wind on various scion cultivars and rootstocks.

\section{ROOTSTOCK/SCION EFFECTS ON TREE ANCHORAGE AND BREAKAGE}

Data from replicated rootstock trials are the primary source of information concerning potential anchorage characteristics for apple trees. During the course of such trials, trees are often exposed to wind events. Although the rootstock is of primary importance, orchard observations indicate that the combined effects of scion and rootstock influence tree anchorage.

Lincoln (1938) was the first to report on hurricane damage in apple orchards. In Sept. 1938, apple orchards from Virginia to New England were damaged by a hurricane with $\approx 25 \mathrm{~cm}$ of rain plus several hours of high winds. Orchards of mature trees on French crab seedling rootstock growing in sod in Connecticut and Massachusetts were evaluated for tree damage. The major factors contributing to damage were exposure to wind and soil depth. One observation that seemed surprising to pomologists at the time was that apple trees were not deeply rooted. Throughout the region large numbers of 'McIntosh' trees were uprooted, but 'Duchess', 'Fameuse', 'Golden Delicious', 'Rhode Island Greening', and 'Northern Spy' were not. Cultivars that were more easily uprooted than 'McIntosh' included 'Red Astrachan', 'Yellow Transparent', and 'Gravenstein'; those more stable than 'McIntosh' included 'Baldwin', 'Ben Davis', and 'Delicious'. When 'McIntosh' was top-worked onto cultivars that were not uprooted, susceptibility to uprooting was similar to that observed for 'McIntosh'. Therefore, tree stability seems to be influenced more by the scion cultivar than by the interstem. Less than $2 \%$ of the trees observed were broken at the graft union. Sometimes roots of broken trees remained firmly in the ground. 'Gravenstein' seemed most susceptible to trunk breakage.

In Aug. 1991, Hurricane Bob hit southern Maine 3 weeks before 'McIntosh' harvest and 6 weeks before 'Delicious' harvest. Following the hurricane, 100 trees each of 12-year-old 'Rogers McIntosh'/M.7 
and spur 'Delicious'/M.7 were evaluated (Schupp, unpublished data). Twenty-six 'McIntosh' trees were uprooted and were subsequently propped; one tree eventually died. Forty-six 'Delicious' trees were propped and 11 subsequently died. Eight years after the hurricane, the mean trunk cross-sectional area (TCSA) of 'McIntosh' trees that did not require propping was $59.4 \mathrm{~cm}^{2}$ vs. $53.2 \mathrm{~cm}^{2}$ for propped trees, a $9 \%$ reduction. The mean TCSA area of 'Delicious' trees that required propping was also 9\% smaller than that of nonpropped trees. Root characteristics of apple trees have not been well studied. However, the fact that uprooting was more prevalent for 'Delicious' than for 'McIntosh' may have been because the rootstocks of spur 'Delicious' trees tend to have fewer lateral roots than do those of 'McIntosh' trees (Barritt, 1988; Rom and Motichek, 1987). The limited rooting also may explain the higher mortality of 'Delicious' trees, some of which were nearly torn free of the soil. For trees that successfully reestablished, the reduction in growth was $9 \%$ for both cultivars despite the difference in the extent of damage from the storm.

Following the same storm, 'Starkspur Supreme Delicious' apple trees in the 1984 NC-140 planting were inspected for wind damage (Schupp et al., 1994). Rootstocks with high yield efficiency leaned more than those producing larger trees (data not shown), but the latter, which were better anchored, lost a larger percentage of the annual yield as a consequence of remaining upright for the duration of the storm (Table 1).

In Massachusetts, high winds from tropical storms in 1970 and 1971 uprooted some trees in experimental plantings and provided an opportunity to compare the anchorage of various rootstock/scion combinations (Greene, 1974). Thirty such combinations, consisting of six rootstocks (M.2, Robusta 5, M.7, MM.106, MM.104, and seedling) and five cultivars ('Puritan', 'Niagara', 'McIntosh', 'Delicious', and 'Golden Delicious'), were evaluated (Table 2). No trees of 'Puritan' and no trees on seedling or MM.106 rootstock were uprooted. Trees on M.7 were most prone to wind damage; of the five cultivars only 'Puritan' did not lean, whereas all of the 'Delicious' trees did so. Based on these observations, Greene (1974) made several suggestions to consider before planting rootstock/scion combinations that are poorly anchored: 1) plant trees that are budded at least $15 \mathrm{~cm}$ high, and plant trees deeper than they grew in the nursery to encourage rooting along the rootstock shank; 2) avoid soil types not favorable for deep rooting; 3 ) avoid planting on windy sites, as such sites may not be most prone to hurricane injury, but severe wind events are likely to occur; 4) provide support for newly planted trees to minimize whipping of the tree and thus encourage adventitious root formation along the entire below-ground portion of the rootstock.

At one time many nurseries budded rootstocks 15 to $25 \mathrm{~cm}$ above ground, but most have discontinued this practice. In well-drained, deep soils, high-budded trees tend to produce a new root system on the shank above the original root system, and anchorage is improved. However, in heavier clay loam and silt loam soils, the original root system may die because of inadequate aeration before the new one can form. Serious loss and stunting of the trees may occur, particularly if the season after planting is wet (Ferree and Carlson, 1987). For this reason, on problem soils trees should not be planted more than 7 to 10 $\mathrm{cm}$ deeper than they grew in the nursery.

In Sept. 1989, Hurricane Hugo passed through southwestern Virginia with wind gusts estimated at 88 to $104 \mathrm{~km} \cdot \mathrm{h}^{-1}$. Although the storm brought only $\approx 5 \mathrm{~cm}$ of rain, the ground was completely saturated from the previous week's rains. After the storm, tree anchorage in several research plantings was evaluated. Observations confirmed previous reports of a strong rootstock/scion interaction. In one block, $88 \%$ of the nonspur 'Delicious'/M.7A trees were uprooted, whereas no 'Golden Delicious'/M.7A or 'Empire'/M.7A were uprooted (Table 3). Only $2 \%$ of the 'Redchief Delicious' trees, a spur-type strain, on M.7A were uprooted. The rootstock/scion interaction was also obvious in the 1984 NC-140 planting, where a spur strain of 'Delicious' was planted on 15 rootstocks and the pollinizers were spur-type strains of 'McIntosh'/M.26 EMLA and 'Golden Delicious'/M.26 EMLA (Table 4). Only $10 \%$ of the 'McIntosh' and 'Golden Delicious' trees, but $40 \%$ of the 'Delicious'/M.26 EMLA trees, were uprooted. Other rootstocks budded with spur 'Delicious' scions exhibiting poor anchorage were C.6 and M.4. In other plantings we also observed severe
Table 1. Effects of rootstock on trunk cross-sectional area (TCA), tree leaning, and fruit drop of 'Starkspur Supreme Delicious' apple caused by hurricane winds in Maine, 1991.

\begin{tabular}{lcccc}
\hline \hline Rootstock & $\begin{array}{c}\text { TCA } \\
\left(\mathrm{cm}^{2}\right)\end{array}$ & $\begin{array}{c}\text { Leaning (angle } \\
\text { from vertical) }\end{array}$ & $\begin{array}{c}\text { No. windfalls/ } \\
\text { kg of yield }\end{array}$ & $\begin{array}{c}\text { Drop } \\
\text { ranking }\end{array}$ \\
\hline Michigan apple clone 1 & 70 & 7 & 1.8 & 3 \\
Seedling & 62 & 7 & 1.6 & 5 \\
Budagovsky 490 & 90 & 7 & 2.4 & 1 \\
Antanovka 313 & 90 & 8 & 1.7 & 4 \\
Malling 7 EMLA & 50 & 16 & 1.5 & 6 \\
Malling 26 EMLA & 36 & 34 & 0.6 & 9 \\
Polish 22 & 5 & 38 & 0.1 & 13 \\
Polish 1 & 49 & 39 & 1.0 & 8 \\
Polish 2 & 17 & 43 & 0.2 & 12 \\
Budagovsky 9 & 24 & 45 & 0.4 & 11 \\
Michigan apple clone 39 & 15 & 56 & 1.1 & 7 \\
C.6 & 28 & 71 & 0.5 & 10 \\
\hline
\end{tabular}

${ }^{\mathrm{z} F r o m: ~ J . ~ S c h u p p, ~ u n p u b l i s h e d ~ d a t a . ~}$

${ }^{y}$ Ranking based on no. windfalls $/ \mathrm{kg}$ of yield.

${ }^{\mathrm{x}} \mathrm{C} .6$ is an open-pollinated seedling of Malling 8 .

Table 2. Effect of rootstock/scion combination on the percentage of apple trees leaning after tropical storms in 1970 and 1971 at Belchertown, Mass. ${ }^{2}$

\begin{tabular}{lrrrrrr}
\hline & \multicolumn{6}{c}{ Rootstock } \\
\cline { 2 - 7 } Scion cultivar & M.2 & Robusta 5 & M.7 & MM.106 & MM.104 & Seedling \\
\hline Puritan & 0 & 0 & 0 & 0 & 0 & 0 \\
Niagara & 0 & 0 & 63 & 0 & 0 & 0 \\
McIntosh & 0 & 17 & 13 & 0 & 0 & 0 \\
Delicious & 57 & 14 & 100 & 0 & 13 & 0 \\
Golden Delicious & 0 & 0 & 13 & 0 & 13 & 0 \\
\hline
\end{tabular}

From: Green, 1974.

tree leaning of 'Gala', 'Stayman', and 'Granny Smith' on M.7A rootstock.

\section{Breakage}

Some rootstocks, especially MARK and G.30, tend to produce weak bud unions with certain scion cultivars. Based on orchard observations and discussions during the annual meetings of the North Central Regional Project-140 technical committee, many pomologists now feel that 'Gala' and 'Golden Delicious' on these rootstocks, and possibly on M.9, must be supported extremely well. When trained to the vertical axe system, two wires may be needed to prevent the tree from twisting in the wind. Many pomologists believe that this will help stabilize the trunks and prevent them from snapping off at the bud union.

\section{SALVAGING INJURED TREES}

No experiments appear to have been designed to evaluate different methods of up-righting apple trees that are leaning or uprooted during a severe wind event. Most recommendations are based on observations in commercial orchards following a storm. Hurricanes and tropical storms often occur just before or during the harvest season. Because labor is usually limiting, growers often decide to upright their trees after harvest, which may be 6 weeks after the storm. In 1994, Hurricane Fran damaged several Virginia orchards, especially in intensive plantings where trees were supported with 48-mm-diameter wooden posts and no wire. Many of the affected trees were not righted until after harvest, 6 or 7 weeks after the storm. Some of the trees were broken at the graft union and many trees had broken roots and were lying flat on the ground. About $5 \%$ of the trees died the next season. Some trees seemed to grow normally, but many grew very poorly for a year and then seemed to recover within 2 or 3 years.

In Sept. 1985, Hurricane Gloria passed through New England and damage to apple trees varied from slightly leaning to complete breakage or blow-down. Because little new information was available to advise apple growers requesting information on caring for injured trees, Autio (1985) offered the following suggestions based on information written in the 1930s for restoring trees to an upright position. A summary of his comments follows. 
1) Salvage work should be completed as soon as possible, because tree roots are very sensitive to cold temperatures. If the temperature drops below $-10^{\circ} \mathrm{C}$ roots may be injured, so trees must be straightened before early winter.

2) It is often not feasible to salvage 20-year-old or older apple trees. Younger trees can recover more easily and have more potentially productive years ahead of them.

3) Trees uprooted with $30 \%$ to $50 \%$ of the root system exposed may not respond well enough to make salvage possible. Growers should give the most immediate attention to the most desirable trees.

4) Any movement of a tree trunk from vertical may result in disruption of the root system. While straightening a tree, attempt to return the root system to its original position to encourage the development of new roots. If the root system has been lifted it may be necessary to remove soil beneath it to allow repositioning. Puddling of the soil with water may improve the success of pulling the tree back to a vertical position, especially with larger trees. Once returned to the vertical position the tree must be secured by wires to stakes or "dead men," positioning these so that prevailing winds do not cause excessive tree movement. After anchoring the tree, the soil should be replaced around the roots. Root development should be encouraged, and mulching may help by stabilizing the soil around the roots.

5) Some trees may be leaning slightly or not at all, but have an area around the trunk where soil has been compacted by trunk movement, leaving a space between the trunk and soil. This area should be filled with soil or gravel to prevent vole injury. Vole control is critical in hurricane-damaged orchards. There may be two reasons that uprooted trees may be more vulnerable to vole injury (R.E. Byers, personal communication). 1) Voles may be displaced as a tree is uprooted, causing the vole population to disperse into areas of the orchard not previously inhabited by voles; 2 ) the loose, moist soil under uprighted trees provides an ideal habitat for voles.

6) Pruning salvaged trees should be delayed until spring, and heavy pruning should be avoided. To encourage recovery of these trees, stresses (drought, heavy cropping, and weed competition) should be minimized for a few years.

Following are some additional suggestions intended for apple growers in New York's Hudson Valley following the same storm (Smith, 1985).

1) As soon as possible, preferably immediately following a rain, straighten trees, because rerooting begins immediately after root damage occurs. Root growth will continue as long as soil temperature remains above $15^{\circ} \mathrm{C}$.

2) After straightening the tree, fill and pack soil and space around the tree trunk to prevent water accumulation and possible early winter freeze damage to exposed root and crown area.

\section{STRAIGHTENING TREES}

Several methods have been used to straighten trees. The most popular method is to attach a rope or chain well up on the trunk. The tree is pulled to the vertical position, taking care not to twist or pull remaining roots from the soil. To prevent tearing the bark, cloth or some other protective material can be placed between the chain and the trunk. The tree is then tied to a post at least $160 \mathrm{~cm}$ long set $\approx 60 \mathrm{~cm}$ in the ground. Shorter stakes probably will provide inadequate support. Sometimes a hole can be drilled through the trunk, and a wire, attached to a large washer, run through the hole and twisted around the stake. Less severely damaged trees can be propped with wooden $5 \times 10-\mathrm{cm}$ construction lumber. Propping is fast and inexpensive in terms of material and labor. Sometimes sandbags are placed on the upwind side to stabilize the tree.
Table 3. Influence of scion/cultivar combination on leaning of apple trees on M.7A and MM.111 rootstocks following Hurricane Bob at Blacksburg, Va., in 1991.

\begin{tabular}{lcccc}
\hline \hline Cultivar & Rootstock & $\begin{array}{c}\text { Age } \\
(\mathrm{yr})\end{array}$ & $\begin{array}{c}\text { Trees } \\
\text { evaluated (no.) }\end{array}$ & $\begin{array}{c}\text { Trees leaning } \\
<45^{\circ}(\%)\end{array}$ \\
\hline Triple Red Delicious & M.7A & 8 & 9 & 88 \\
Golden Delicious & M.7A & 8 & 24 & 0 \\
Jerseymac & M.7A & 8 & 9 & 11 \\
Empire & M.7A & 8 & 8 & 0 \\
Redchief Delicious & MM.111 & 7 & 170 & 2 \\
\hline
\end{tabular}

Table 4. Influence of scion/rootstock combination on leaning $\left(<45^{\circ}\right)$ of apple trees of the cultivars Starkspur Delicious (SS), Spur Golden Delicious (GD), and McIntosh (M) following Hurricane Bob at Blacksburg, Va., in 1991.

\begin{tabular}{cccccc}
\hline \hline \multicolumn{7}{c}{ Trees leaning (\%) } \\
\hline $0-10$ & 20-30 & $40-50$ & $60-79$ & $80-90$ & 100 \\
\hline SS/Bud.490 & SS/Seedling & SS/Ant. 313 & --- & SS/M.4 & SS/C.6 \\
SS/P.22 & SS/Bud.9 & SS/CG.24 & --- & --- & --- \\
GD/M.26 & SS/CG.10 & SS/M.26 EMLA & --- & --- & --- \\
M/M.26 & SS/P.1 & SS/MAC.1 & --- & -- & -- \\
--- & SS/M.7 EMLA & SS/MAC.39 & --- & --- & --- \\
--- & --- & SS/P.2 & --- & --- & --- \\
--- & --- & SS/P.16 & --- & --- & --- \\
--- & --- & SS/P.18 & --- & -- & -- \\
\hline
\end{tabular}

\section{SUMMARY}

More research is needed concerning the proper handling of fruit trees following injurious climatic events. Severe wind, drought, and low winter temperatures occur too irregularly to use them as experimental treatments, and experiments that mimic such events are difficult to design. Although such events may compromise data from the original experiments, these infrequent events may be used to gain information when they affect existing trials. Rootstocks, cultivars, rootstock/scion interactions, training systems, and other pertinent treatments should be evaluated for their influence on injury. Where possible, a new experiment can be superimposed on the original one by applying various treatments to injured trees. Growth and yield data collected for several years after injury could then be used to develop recommendations for treating injured trees. An interesting area of research, which may lead to grower recommendations, is to quantify the effects of rootstock and scion cultivar on amount and distribution patterns of roots.

\section{Literature Cited}

Autio, W.R. 1985. Hurricane damage. In: D.A. Marini (ed.). Fruit Nwsl., Plymouth Co. Coop. Ext., Univ. of Massachusetts. 17 Oct. 1985.

Barden, J.A. and R.P. Marini. 1998. Growth and cropping of young apple trees as affected by heading and support of the central leader. HortScience 33:39-41.

Barritt, B.H. 1988. Influence of strain of 'Delicious' apple on root development of 1-year-old trees. HortScience 23:316-317.

Elfving, D.C. and E.D. McKibbon. 1992. Tree support-Another management tool for apple growers. Compact Fruit Tree 25:12-14.

Ferree, D.C. and R.F. Carlson. 1987. Apple rootstocks, p. 107-143. In: R.C. Rom and R.F. Carlson (eds.). Rootstocks for fruit crops. Wiley, New York.

Greene, D.W. 1974. Effect of rootstock-scion combination on anchorage of apple trees. Compact Fruit Tree 7:27-28.

Lincoln, F.B. 1938. Some apple tree stock relationships seen in New England after 1938 hurricane. Proc. Amer. Soc. Hort. Sci. 36:102-109.

Rom, R.C. and G.R. Motichek. 1987. Cultivar effect on adventitious root development of clonal apple rootstocks. HortScience 22:57-58.

Schupp, J.R., M.A. Schupp, and M.M. Bates. 1994. Growth and fruiting of 'Delicious' apple on clonal rootstocks in the 1984 NC-140 planting in Maine. Fruit Spurs, Univ. of Maine, Spring 1994:11-13.

Smith, W. 1985. Harvest 1985: Hurricane Gloria-The aftermath southern Hudson Valley region damage. Fruit Growers Nswl., Cornell Univ. 